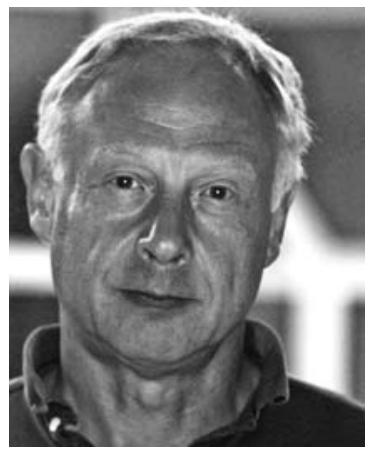

\title{
A Conversation with Davor Solter
}

\author{
INTERVIEWER: JIAYING TAN \\ Scientific Editor, Cell
}

Davor Solter is a Visiting Professor in the Siriraj Center of Excellence in Stem Cell Research at Mahidol University, and Emeritus Director of the Max Planck Institute of Immunobiology and Epigenetics.

Jiaying Tan: How did you get interested in embryonic development?

Dr. Solter: I was teaching anatomy at a medical school in Zagreb in the late 1960s and I realized that one doesn't really do much experimenting in anatomy, especially not in gross anatomy. A friend in the Department of Biology was working on mammalian development, which was very unusual, because mammalian embryos were considered to be too small and too difficult to work with. This was at the very beginning of molecular biology: ultracentrifuges and stuff like that. Obviously, for that you need buckets of embryos, so everything was done on sea urchins and Xenopus.

I started working on early mouse development by asking what would happen if you transferred early postimplantation embryos, the gastrula, to an extrauterine site? Similar experiments in rats had hinted there would be a very small kind of growth with many mixed tissues. To my surprise, if the embryo was transplanted onto the kidney capsule it turned into a malignant teratocarcinoma. After a few months, the tumors were almost as big as the hosts and eventually would kill them. We realized that if you could make tumors out of embryos, then maybe you could make cell lines out of embryos, and that's how we started.

Jiaying Tan: You're one of the pioneers of the whole concept of imprinting. What's your view of how the concept of imprinting has evolved over time and how people see it now?

Dr. Solter: We started those experiments in the early 1980s. I use imprinting as an example of "real discovery." People mention finding the structure of DNA as a great scientific finding, but was it a real discovery? We knew DNA existed and that it had a structure. It just needed to be defined. Imprinting was totally different. It was a new idea and the reason we started doing nuclear transfers and looking at male versus female pronuclear structure.

We wanted to explain why parthenogenesis doesn't work in mammals. We were expecting that an embryo to which you'd transferred two male or two female pronuclei would develop perfectly well because they were diploid embryos that had all the necessary chromosomes. The usual problems involved in parthenogenic failure were eliminated because the zygotes were fertilized normally, so any contributions from the sperm were already there. To our surprise, they never developed. It took us, Jim McGrath and me, probably two or three years to convince ourselves that these embryos were not going to develop and that there must be something different between the male and the female genome. That was the beginning of imprinting. The results were completely unexpected because none of the classical Mendelian genetics suggested that something like that should exist.

Even at that time, we were fairly cautious. We thought it most likely was related to gene expression, but there was no evidence for that until the first imprinted gene was found almost 10 years later. That was the first time that we could really say that imprinting is truly a genetically based mechanism. Interestingly, imprinting started people thinking seriously about epigenetics, which is now so prevalent.

Even with everything we've learned over the last 30 years, there are still some basic questions we don't even know how to begin to answer. Mainly, how the oocyte or sperm select the genes to be imprinted during gametogenesis. Most people just say that it's because they become methylated, but methylation is obviously a later step that firmly established the imprint. It doesn't answer the question as to how the cell knows which genes to methylate. How is the choice made? How does the oocyte receive these genes in a completely native state and treat some of them differently than all others? Because we don't even know how to approach it, everybody works on how the imprint is maintained. Nobody wants to try to see what made the preimprinted genes different from others.

Also, imprinting is certainly distinctive to mammals. Although it could be present in some form in flowering plants, it's not present in any other organisms. Was im- 
printing invented as a mammalian approach to development? Evolution rarely finds an optimal solution. It finds $a$ solution, and then we are stuck with that solution forever. Reproduction in mammals faced a major problem: embryos, which are entirely dependent on and have to develop completely in another organism. Normally, the first job of an embryo is to appoint a different portion of itself as a trophectoderm. If they don't make a trophectoderm, the embryo will fail. Was imprinting evolutionarily necessary for trophectoderms to develop? The most popular theory is that the trophectoderm balances a maternal/ embryonic conflict. I always feel that fetus and mother cooperate, and they very rarely have opposite interests. Still, it's a possibility.

Jiaying Tan: People talk about embryonic stem (ES) cells and reprogramming from different aspects. There's different ways of reprogramming, and people are thinking about whether it's therapeutically applicable. As one of the scientists who started working on this field, how do you see it evolving?

Dr. Solter: When ES cells were derived in mice, there was no general interest among the public. Human ES cells were developed by my graduate student James Thomson, coincidentally at the same time Dolly happened. Dolly created a sudden interest, as if nobody had thought of doing nuclear transfer and cloning before, even though it had been going on for 10 or 15 years. Dolly suddenly caught the public imagination, as did the human ES cells. They were immediately seen as some sort of panacea, that they would cure everything and eliminate aging. I remember a front-page article in The New York Times Magazine that said, "Racing Toward Immortality."

Today, scientifically, we have very little use for human ES cells. Most of that work can be done in mouse. Meanwhile, the therapeutic applications of human ES cells derived by cloning were mired for a long time in the discussion over whether it was ethical to make and kill embryos just to cure people. That ethical mess was resolved by the development of induced pluripotent stem
(IPS) cells. Now the only question is if the theoretical potential of IPS cells is realistic. Are we really going to be able to cure people? The questions of how to best reprogram IPS cells are similar to those in ES cells. Determining their differentiation potential is, in a sense, irrelevant. The question is, can you take a cell from an individual and make it into another cell that will deal with a disease afflicting that individual?

Let's say you needed to replace your cardiomyocytes. It's totally irrelevant whether this cell can also make neurons. You don't need neurons. If I need neurons, it's totally irrelevant whether they can make cardiomyocytes. Unfortunately, the research is not concentrating on the crucial issues of how to make reprogramming therapeutically feasible. How are we going to induce correct differentiation? What clinical trials need to be conducted before we can inject those cells into people? How are we going to send those cells to the right place in the organism? These cells have a strange history. They could have started as fibroblasts, been treated to change them into IPS cells, then treated again to change them into cardiomyocytes. Does this totally destabilize the genomes once you've injected these cells into heart? Some of them might be okay and make cardiomyocytes the way you'd hoped, but some might suddenly start making bone. Now you have this misdifferentiation in a place where you don't want it. How can we be sure that they will not make tumors? We do these experiments in mice and they're fine, but mice have very short life spans. We are going to treat children with these cells. What are the safety issues?

All those questions are not attracting as much attention as they should, and they will all have to be dealt with because this is totally new paradigm. All the classical ways of testing drugs and medical procedures have an aspect that, if something bad is happening, you stop the trial. If you inject cells, there is no way of getting them out again. I foresee a lot of problems. The potential is great, but the issues are also very important and not quite resolved. 


\section{$\$_{\text {CSH }}^{\infty}$ Cold Spring Harbor Symposia SYMPOSIA On Quantitative Biology}

\section{A Conversation with Davor Solter}

Cold Spring Harb Symp Quant Biol 2015 80: 346-347

Access the most recent version at doi:10.1101/sqb.2015.80.030130

\section{License}

Email Alerting Receive free email alerts when new articles cite this article - sign up in Service the box at the top right corner of the article or click here. 